\title{
Laparoscopic Appendectomy versus Glove Single Port Laparoscopic Appendectomy in Pediatrics under Spinal versus General Anesthesia. A controlled Randomized Study
}

\author{
${ }^{1}$ Rafik Yousef Shalaby, ${ }^{2}$ Magdy Mahmoud Mostafa, ${ }^{3}$ Ahmed Said Abd El-Rahman, \\ ${ }^{1}$ Mabrouk Maowed Akl, ${ }^{1}$ Islam Mohamed Abd Al-Monem \\ ${ }^{1}$ Department of Pediatric Surgery, ${ }^{2}$ Department of General Surgery, ${ }^{3}$ Department Anesthesia and Intensive Care, \\ Faculty of Medicin, Al-Azhar University
}

Corresponding author: Islam Mohamed Abd Al-Monem, Mobile: 01014661490; Email: drislammakhlouf@gmail.com

\begin{abstract}
Background: The glove single-port laparoscopic appendectomy it is a novel SILS technique which is extremely cheaper than the other commercial devices. Objective: this study aimed to compare between conventional laparoscopic appendectomy (CLAP) and glove single port laparoscopic appendectomy (GSPLAP) under tow different anesthetic technique. Patients and Methods: this study of laparoscopic appendectomy was conducted over thirty six children $(n=36)$. All patients were randomized into 4 groups by a random-number table sequence after giving informed parental consent. The allocations will be contained in opaque sequentially numbered closed envelopes and every patient drew an envelope. Results: Two cases of GSPLAP were converted to multi-port due to difficult accessibility of the appendix and adhesions (suppurative appendicitis). The Mean operative time for CLAP was significantly lower than GSPLAP procedure. For CLAP was $38.39 \pm 10.12 \mathrm{~min}$ (ranged from 26 to $75 \mathrm{~min}$ ) and was $49.11 \pm 11.98 \mathrm{~min}$ (ranged from 38 to $86 \mathrm{~min}$ ) for GSPLAP. We observed that GSPLA was less painful significantly than CLAP for the first postoperative hours $(\leq 3 \mathrm{hrs})$ the time of postoperative needs of analgesia in pt. underwent LA under SA is delayed. Conclusion: Using a combination of $0.5 \%$ hyperbaric bupivacaine and a fentanyl provided effective anesthesia for laparoscopic appendectomy with low-pressure Co2 Pneumoperitoneum. It offers better pain management for the patients, earlier recovery and less operating room costs. We recommend an increasing use of spinal anesthesia for laparoscopic appendectomy especially in patients with risks for general anesthesia.
\end{abstract}

Keywords: acute appendicitis, general anesthesia, post- operative nausea and vomiting, spinal anesthesia

\section{INTRODUCTION}

Acute appendicitis (AA) is a common cause of acute abdominal pain with a life- time incidence and it was ranged between 79\%.Approximately $20-30 \%$ of children with acute abdominal pain referred to pediatric surgical services have AA. Another 50\% have benign, selflimiting, non- specific abdominal pain. The incidence of AA varies per age group ranging from one to six per 10,000 children annually under 4 years of age to 19 to 28 per 10,000 children under the age of 14 years ${ }^{[1,2]}$.

The treatment of AA remained essentially unchanged since its first description by Charles McBurney in 1889. Appendectomy by McBurney's incision remained the procedure of choice for nearly a century until 1983 when Kurt Semm offered an alternative, laparoscopic appendectomy (LA) ${ }^{[3-5]}$.

Since its first description in the early 1980 s LA has advanced to be the treatment of choice for both complicated and uncomplicated appendicitis, with increasing numbers of procedures performed per year. Many advantages of laparoscopic surgery have been documented over to open appendectomy (OA). It requires small incisions and gives good visualization, it also gives better access to reach the organs in abdomen, as well as fast recovery in the post- operative period ${ }^{[6,7]}$.

Single incision laparoscopic surgery (SILS) attempts to evolve laparoscopy with the aim of quicker recovery, less pain and better patient satisfaction. By reducing trauma to the abdominal wall, it is potentially offer better outcomes than even conventional laparoscopic appendectomy. The glove single-port laparoscopic appendectomy it is a novel SILS technique modified by the introduction of a single port made with a surgical glove.The device allows simultaneous passage of several laparoscopic instruments through one small incision. General anesthesia (GA) being the only suitable technique for laparoscopic surgeries needs a relook. Some complications as pressor response to endotracheal intubation, increased release of stress hormones, sore throat, post-operative pain, post- operative nausea and vomiting (PONV) are from the disadvantages of using $\mathrm{GA}^{[8-14]}$.

Spinal anesthesia (SA) has the advantage of providing analgesia and total muscle relaxation in a conscious and compliant patient and an uneventful postoperative recovery. At the same time, it also protects against the potential complications of (GA). Despite these advantages, regional anesthesia is still preferred only for 
patients who are at high risk for general anesthesia, and the majority of surgeons still prefer doing both open and laparoscopic procedures under GA. The most of the publications and textbooks on laparoscopic surgery cite GA as the only anesthetic option for abdominal laparoscopic surgery. But, lately, occasional reports of laparoscopic surgery being performed under regional anesthesia (spinal or epidural) in selected patients had started ${ }^{[15]}$.

The advantages of SA over GA was that the patient is awake and oriented at the end of the procedure. Second, the absence of general anesthetic side (e.g., nausea and vomiting) and less pain experienced due to the effect of neuraxial analgesia. Hird patients that had received SA tend to ambulate earlier than patients receiving GA. Finally, complications related to intubation and/or extubation is avoided in spinal anesthesia for patients undergoing laparoscopic interventions Combining a minimally invasive surgical procedure with a less invasive anesthetic technique appears, theoretically, to further enhance the advantages of the operation ${ }^{[16]}$.

\section{AIM of the STUDY}

The aim of this study was to compare conventional laparoscopic appendectomy versus Glove single port laparoscopic appendectomy in pediatric patients using a homemade glove single port under spinal versus general anesthesia and to test the possibility of application of spinal anesthesia during laparoscopic appendectomy in children.

\section{PATIENTS AND METHODS}

This prospective controlled randomized study of laparoscopic appendectomy was conducted over thirty six children $(n=36)$ at the Pediatric Surgery Department, Al-Azhar University Hospitals, Cairo, over a period of 1 year from January 2018 to September 2018. All patients with the confirmed diagnosis were included in this study. The study was approved by the Ethics Board of Al-Azhar University.

All patients were randomized into 4 equal groups by a random-number table sequence after giving informed parental consent. The allocations were contained in opaque sequentially numbered closed envelopes and every patient drew an envelope. The study contained 4 groups:
- Group (I): subjected to CLAP under GA. [12 patients]

- Group (II): subjected to CLAP under SA. [6 patients]

- Group (II): subjected to GSPLAP under GA. [11 patients]

- Group (IV): subjected to GSPLAP under SA. [7 patients]

\section{Inclusion criteria:}

Power of the study: the minimal sample number was 18 cases for each group. Assuming a drop-out ratio of $5 \%$ the sample size will be 20 cases for each group Patients are divided in to two equal groups: Number: thirty six cases (36 cases) 18 in each group. Age: under 16 years old. Sex: both. Cases of the study: cases of acute appendicitis, cases of chronic appendicitis and patients scheduled for interval appendectomy.

Exclusion criteria: cases of appendicular abscess or mass and cases of appendicitis complicated with diffuse peritonitis.

following:

All patients were subjected to the

Preoperative assessment: full history taking and full clinical examination

Investigations: Laboratory: complete blood count, $\mathrm{C}$ - reactive protei and urine analysis.

Radiological: 1-Pelvi-abdominal ultrasound. 2- Pelvi-abdominal X-ray. 3Computed tomography (spiral CT) if needed.

Modified score- Pediatric Appendicitis Score (PAS)

Pre-operative preparations: the patient was fasting 6 hours, fluid and electrolyte balance and Broad spectrum antibiotics were administrated Operative techniques:

Anesthesia $\mathrm{mg} / \mathrm{kg}$.

Preoperative preparations: atropine: 0.01

Induction: Spinal: heavy marcaine $0.5 \%$. General: fentanyl $1 \mathrm{ug} / \mathrm{kg}+$ propofol $2 \mathrm{mg} / \mathrm{kg}$ + tracum $0.5 \mathrm{mg} / \mathrm{kg}$. Maintenance: sevoflurane $2 \%$ + intraoperative IV fluids, monitoring of (Blood pressure, pulse, end tidal $\mathrm{CO} 2$ and $\mathrm{O} 2 \%$ ).

Recovery: reversal of muscle relaxant.

\section{Surgical technique}

\section{A- Conventional laparoscopic appendectomy (CLAP)}

We started the technique by trans umbilical vertical incision about $0.5 \mathrm{~cm}$. A $5 \mathrm{~mm}$ trocar was 
introduced by open method for telescope 5 with 30 degree. Pneumoperitoneum was established and the abdomen was insufflated with $\mathrm{CO} 2$ by gas flows at 4L per minute with intra-abdominal pressure being maintained between 8 and $12 \mathrm{~mm} \mathrm{Hg}$ according to the age. The abdominal cavity was inspected and two 5 or $3 \mathrm{~mm}$ working ports were introduced under laparoscopic guidance. One was placed to the right upper quadrant at or above the level of the umbilicus and the other to the left lower quadrant to the level of the iliac spine. The appendix was

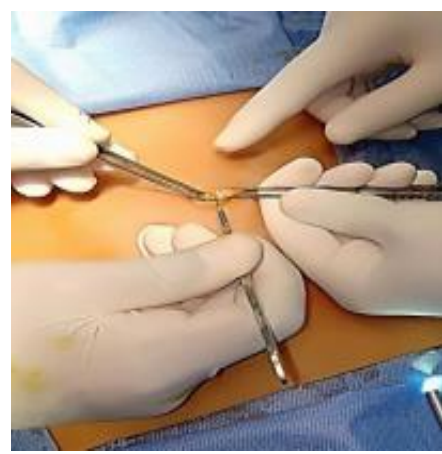

A

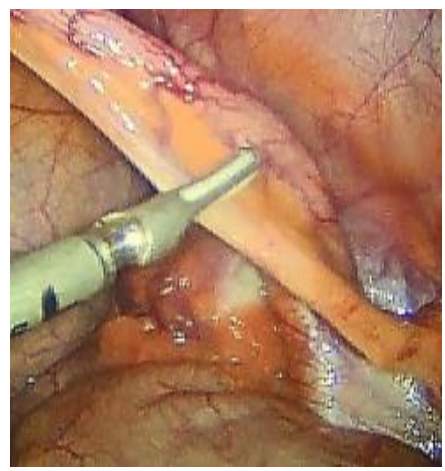

E

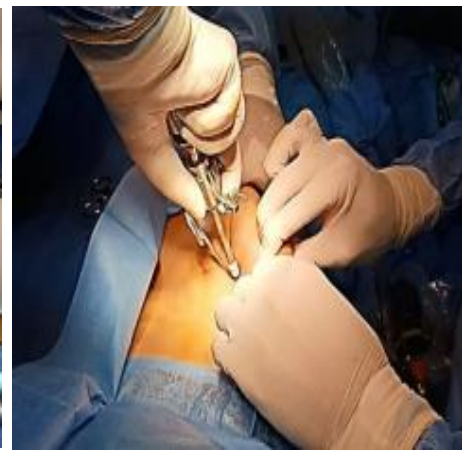

B

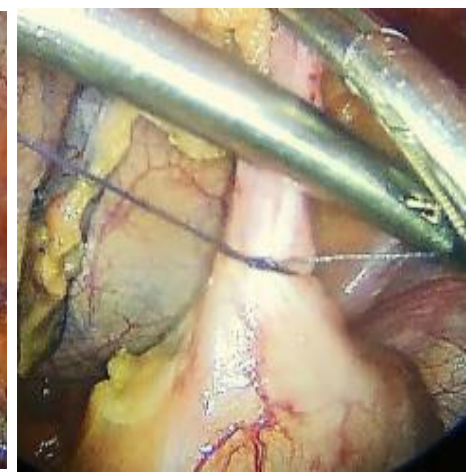

$\mathrm{F}$

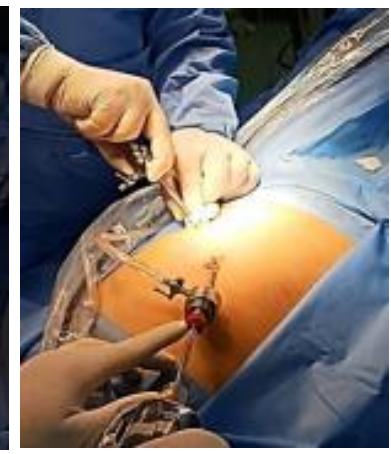

C

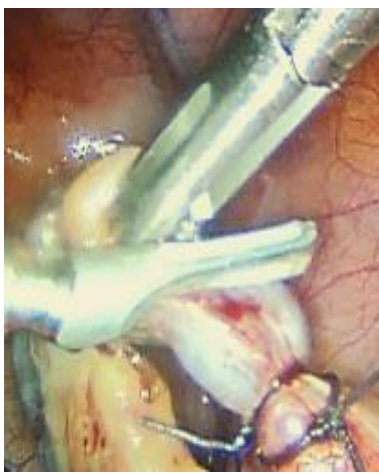

G

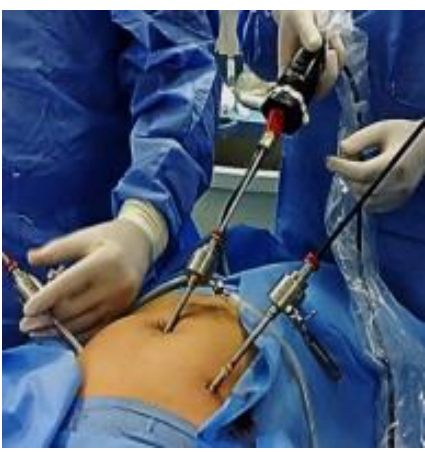

D

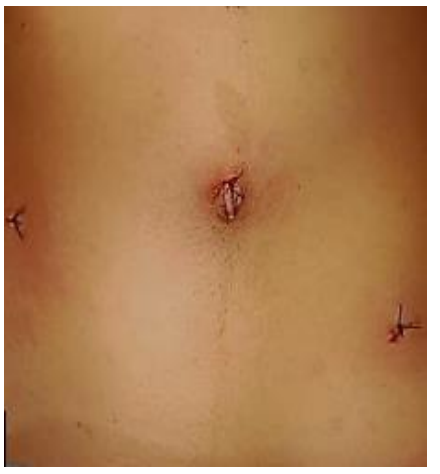

$\mathrm{H}$

Figure (1): A) Umbilical incision. B) Umbilical port. C) Acsessory port. D) Port sites, E) electocutarization of meso appendix. F,G) appendicular base ligation and division. $\mathrm{H}$ ) wound closuer

\section{B- Glove single port laparoscopic appendectomy (GSPLAP)}

We made the trans-umbilical glove port by a flexible plastic ring (FR), a rigid larger plastic ring (RR), with different diameters, pair of powderfree surgical gloves and conventional standard laparoscopic $5 \mathrm{~mm}$ trocars. At the beginning of the procedure, the fingertips of the glove are cut-off where the trocars were inserted and fixed. Then, the open end of the glove is passed through the FR and turned around it in the middle of the glove. A 2 - cm longitudinal trans-umbilical skin incision was done to introduce the FR covered by the glove into the abdominal cavity. The open end of the glove surrounds then closely the RR. Pneumoperitoneum was established and the abdomen was insufflated as described before in the first group. A conventional standard laparoscopic instruments 5 or 3- $\mathrm{mm}$ and 5-mm 30 degree telescope were used to perform SPLA. The Meso-appendix was divided close to the appendicular wall in an anti-grade fashion with the Standard hook using a Harmonic scalpel. The appendicular base was ligated with two applications of vicryl 2/0 handmade endo-loop. The appendix was retrieved through the umbilical port site. After removal of the glove port. Deflation 
of the abdomen and the umbilical fascia is closed with $2 / 0$ Vicryl suture and the subcutaneous layer

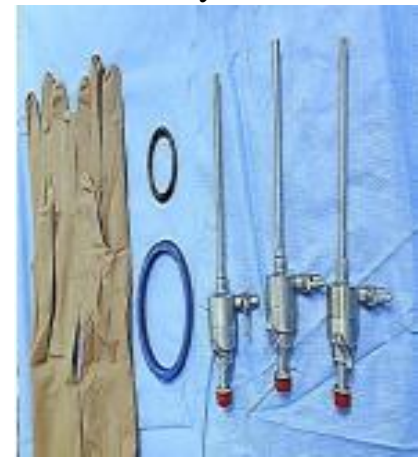

A

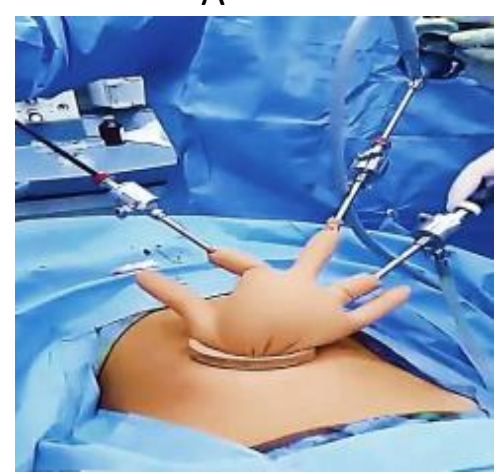

$\mathrm{E}$

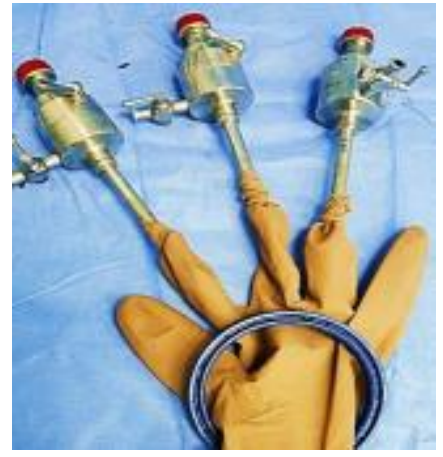

B

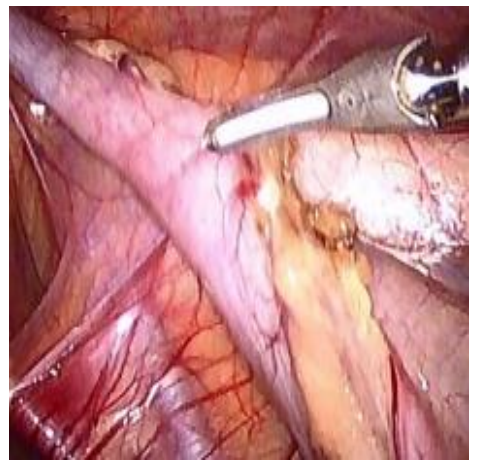

$\mathrm{F}$ and the umbilical skin are sutured with 4/0 Vicryl( Figs. 9-15).

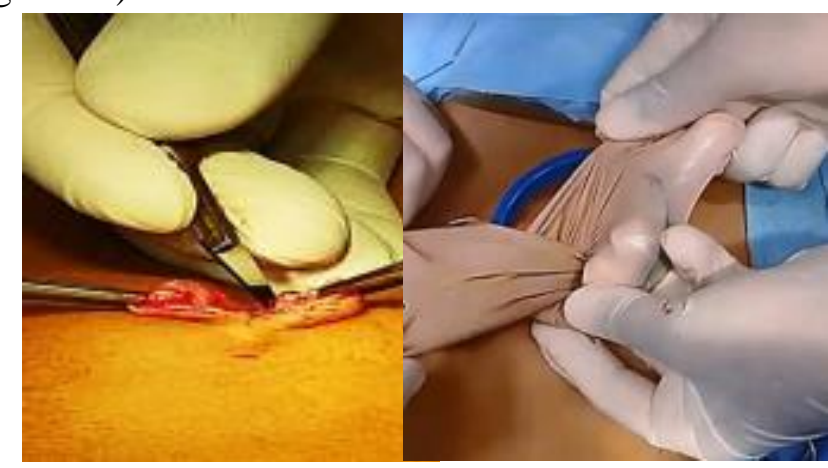

C
D

Figure (2): A,B) A homemade glove single port. C) Umbilical incision. D) inertion of the glove port. E) Instuments position. F) Electocutarization of meso appendix. G) Wound closuer.

Postoperative: time for first postoperative need of analgesia (NSID).

Postoperative management: patient was kept NPO till bowel regain its activity, patient was received intravenous fluids, antibiotics and analgesics NSAIDs as needed for pain.

Follow-up: early and late postoperative results, including complications and cosmetic outcomes, have been recorded and analyzed. After discharge, all patients were seen at 1week intervals for estimations of pain, complications, subjective full recovery (defined as return to normal daily activities), time for return to work, and duration of sick leave. Additional outpatient clinic visits or any procedures were scheduled whenever new symptoms developed. Six-month follow-up has been completed, with assessment of the cosmetic results the incidence of development of incisional hernias in the umbilical scar,

based on the possibility of higher incidence of such hernias after the single-incision approach.

\section{RESULTS}

\section{1-Demografic data:}

The demographic data for all patients are shown in table [1] which shown no statistically significant difference between groups.

Table 1: Comparison between CLA and Glove single port LA according to demographic data.

\begin{tabular}{|c|c|c|c|}
\hline $\begin{array}{c}\text { Demographic } \\
\text { Data }\end{array}$ & $\begin{array}{l}\text { CLAP } \\
(n=18)\end{array}$ & GSPLAP $(n=18)$ & p-value \\
\hline \multicolumn{3}{|l|}{ Sex } & \multirow{3}{*}{0.502} \\
\hline Female & $7(39 \%)$ & $9(50 \%)$ & \\
\hline Male & $\mathbf{1 1}(61 \%)$ & $9(50 \%)$ & \\
\hline \multicolumn{3}{|l|}{ Age (years) } & \multirow{3}{*}{1.000} \\
\hline$\leq 10$ years & $3(17 \%)$ & $3(17 \%)$ & \\
\hline$>10$ years & $\mathbf{1 5}(83 \%)$ & $15(83 \%)$ & \\
\hline Mean \pm SD & $11.7 \pm 2.9$ & $\mathbf{1 2 \pm 1 . 6}$ & \multirow{2}{*}{0.624} \\
\hline Range & $5-14$ & $9-15$ & \\
\hline
\end{tabular}


The operative accessibility of the appendix:

27 patients had easy accessibility and 9 patients had difficulty (Adhesions).

\section{Conversion:}

Laparoscopic appendectomy was successfully done in all cases of the study. There was no conversion to open appendectomy in each group. 2 accessory ports were needed in 2 cases for GSPLAP since converted to CLAP due to difficult accessibility of the appendix.

\section{Drain:}

One drain was inserted in a case for each group due to blood accumulation after dissection of extensive adhesions (in a case of GSPLAP but after conversion to CLAP).

\section{The Mean operative time (min):}

It is the time between beginning with the skin incision and ending with wound closure .The Mean operative time for CLAP was significantly lower than GSPLAP procedure. For CLAP was $38.39 \pm 10.12$ $\mathrm{min}$ (ranged from 26 to $75 \mathrm{~min}$ ) and was $49.11 \pm 11.98$ $\mathrm{min}$ (ranged from 38 to $86 \mathrm{~min}$ ) for GSPLAP.

Table 2: Comparison between general and spinal anesthesia according to vital signs in each group.

\begin{tabular}{|c|c|c|c|}
\hline Intra operative data & $\begin{array}{l}\text { CLAP } \\
(n=18)\end{array}$ & $\begin{array}{c}\text { GSPLAP } \\
(n=18)\end{array}$ & $\begin{array}{c}\text { p- } \\
\text { value }\end{array}$ \\
\hline \multicolumn{3}{|l|}{\begin{tabular}{|l|} 
Conversion \\
\end{tabular}} & \multirow{3}{*}{0.146} \\
\hline Converted to multi-port & $\mathbf{0}(0 \%)$ & $2(11 \%)$ & \\
\hline $\begin{array}{l}\text { Converted to open } \\
\text { appendectomy }\end{array}$ & $\mathbf{0}(0 \%)$ & $\mathbf{0}(0 \%)$ & \\
\hline \multicolumn{3}{|l|}{ Drain } & \multirow{3}{*}{1.000} \\
\hline No & $\begin{array}{c}17 \\
(94.4 \%)\end{array}$ & $17(94.4 \%)$ & \\
\hline One drain inserted & $\mathbf{1}(5.6 \%)$ & $1(5.6 \%)$ & \\
\hline \multicolumn{3}{|l|}{$\begin{array}{l}\text { Operative accessibility of } \\
\text { the appendix }\end{array}$} & \multirow{3}{*}{0.248} \\
\hline Difficult due to adhesions & $6(33 \%)$ & $3(17 \%)$ & \\
\hline Easy & $\mathbf{1 2}(67 \%)$ & $\mathbf{1 5}(83 \%)$ & \\
\hline \multicolumn{3}{|l|}{ Mean operative time (min) } & \multirow{3}{*}{$0.006 *$} \\
\hline Mean \pm SD & $38 \pm 10$ & 49 \pm 12 & \\
\hline Range & $26-75$ & $38-86$ & \\
\hline \multicolumn{3}{|l|}{ Rate of success } & \multirow{3}{*}{0.146} \\
\hline Failed & 0 $(0 \%)$ & $2(11 \%)$ & \\
\hline Successfully done & $18(100 \%)$ & $16(89 \%)$ & \\
\hline
\end{tabular}

P-value $>0.05 \mathrm{NS}$; *p-value $<0.05 \mathrm{~S}$;

\section{Post-operative hospital stay:}

The mean postoperative hospital stay was $33.7 \pm 9.90$ hours for CLAP Groups and 29 \pm 8.46 hours for GSPLAP. Most of patients 11 (61\%) for CLAP were discharged from hospital within the first 36 hours and most of patients $12(67 \%)$ for GSPLAP were discharged from hospital within the first 24 hours.

Table 3: Comparison between Groups I: CLA and group II: Glove single port LA according to postoperative hospital stay.

\begin{tabular}{|c|c|c|c|}
\hline $\begin{array}{l}\text { Post-operative } \\
\text { Hospital stay }\end{array}$ & $\begin{array}{l}\text { CLAP } \\
(n=18)\end{array}$ & $\begin{array}{c}\text { GSPLAP } \\
(\mathrm{n}=18)\end{array}$ & $\begin{array}{c}\text { p- } \\
\text { value }\end{array}$ \\
\hline $\begin{array}{l}\text { Hospital stay } \\
\text { (hrs.) } \\
\text { Mean } \pm \text { SD }\end{array}$ & 33.7 \pm 10 & $29 \pm 8.5$ & \multirow[t]{2}{*}{$0.037 *$} \\
\hline Range & $18-48$ & $24-48$ & \\
\hline $\begin{array}{l}\text { Hospital stay } \\
\text { (hrs.) category }\end{array}$ & & & \multirow{3}{*}{$0.035 *$} \\
\hline$\leq 24 \mathrm{hrs}$ & $7(39 \%)$ & $12(67 \%)$ & \\
\hline$>24 \mathrm{hrs}$ & $11(61 \%)$ & $6(33 \%)$ & \\
\hline
\end{tabular}

P-value <0.05 S;

\section{Post-operative complications:}

The overall postoperative complication rate was $11 \%(\mathrm{n}=2)$ for CLAP and $0 \%(\mathrm{n}=0)$ for GSPLAP. Postoperative umbilical cellulitis developed in tow patients in the CLAP 11\% ( $\mathrm{n}=$ 2) and they were treated with wound care and oral antibiotics on an outpatient basis. Postoperative ileus was seen in tow patients $11 \%$ $(n=2)$ of the CLAP groups and there was no mortality in either group

Table 4: Comparison between CLA and Glove single port LA according to postoperative complications

\begin{tabular}{|l|c|c|c|}
\hline $\begin{array}{c}\text { Post-operative } \\
\text { complications }\end{array}$ & $\begin{array}{c}\text { CLAP } \\
(\mathbf{n = 1 8})\end{array}$ & $\begin{array}{c}\text { GSPLAP } \\
(\mathbf{n = 1 8})\end{array}$ & $\begin{array}{c}\text { p- } \\
\text { value }\end{array}$ \\
\hline Port site infection & $\mathbf{0}(0 \%)$ & $\mathbf{0}(0 \%)$ & 1 \\
\hline Umbilical cellulitis & $\mathbf{2}(11 \%)$ & $\mathbf{0}(0 \%)$ & 0.146 \\
\hline Ileus & $\mathbf{2}(11 \%)$ & $\mathbf{0}(0 \%)$ & 0.146 \\
\hline Seroma & $\mathbf{0}(0 \%)$ & $\mathbf{0}(0 \%)$ & 1 \\
\hline Incisional hernia & $\mathbf{0}(0 \%)$ & $\mathbf{0}(0 \%)$ & 1 \\
\hline Mortality & $\mathbf{0}(0 \%)$ & $\mathbf{0}(0 \%)$ & 1 \\
\hline
\end{tabular}

P-value >0.05 NS;

\section{Postoperative pain and needs of analgesia:}

UnderGA: the mean Time for first postoperative need of analgesia NSAID was $3.3 \pm 2.5$ (Hrs) ranged from 0.5 to $6 \mathrm{hrs}$.

Under SA: the mean time for first postoperative need of analgesia NSAID was $6.54 \pm 2.54$ (hrs) ranged from 4 to $12 \mathrm{hrs}$ 
Tab. 5: Comparison between general anesthesia and spinal anesthesia according to postoperative pain and needs of analgesia

\begin{tabular}{|c|c|c|c|}
\hline $\begin{array}{c}\text { Postoperative pain and } \\
\text { needs of analgesia }\end{array}$ & $\begin{array}{c}\text { General } \\
(\mathrm{n}=12)\end{array}$ & $\begin{array}{c}\text { Spinal } \\
(n=6)\end{array}$ & p-value \\
\hline \multicolumn{3}{|l|}{ Postoperative pain (hrs) } & \multirow{3}{*}{$<0.001 * *$} \\
\hline Mean \pm SD & $2.9 \pm 2.4$ & $7 \pm 1$ & \\
\hline Range & $0.5-\mathrm{a} 6$ & $6-a 8$ & \\
\hline \multicolumn{3}{|l|}{ Category } & \multirow{5}{*}{$<0.001 * *$} \\
\hline Shortly after & $9(39 \%)$ & $\mathbf{0}(0 \%)$ & \\
\hline$\leq 3$ hours & $6(26 \%)$ & $\mathbf{0}(0 \%)$ & \\
\hline$\leq 6$ hours & $8(35 \%)$ & $6(46 \%)$ & \\
\hline$<8$ hours & $\mathbf{0}(0 \%)$ & $7(54 \%)$ & \\
\hline \multicolumn{3}{|l|}{$\begin{array}{l}\text { Time for first } \\
\text { postoperative need of } \\
\text { analgesia NSAID (hrs) }\end{array}$} & \multirow{3}{*}{$<0.001 * *$} \\
\hline Mean \pm SD & $\mathbf{3 . 3} \pm 2.5$ & $6.54 \pm 2.5$ & \\
\hline Range & $0.5-6$ & $4-12$ & \\
\hline \multicolumn{3}{|l|}{ Category } & \multirow{5}{*}{$0.007 *$} \\
\hline Shortly after & $8(35 \%)$ & $\mathbf{0}(0 \%)$ & \\
\hline$\leq 3$ hours & $\begin{array}{c}\mathbf{4} \\
(17.4 \%)\end{array}$ & $\mathbf{0}(0 \%)$ & \\
\hline$\leq 6$ hours & $\begin{array}{c}11 \\
(48 \%)\end{array}$ & $\begin{array}{c}11 \\
(85 \%) \\
\end{array}$ & \\
\hline$\leqslant 12$ hours & $\mathbf{0}(0 \%)$ & $\begin{array}{c}\mathbf{2} \\
(15.4 \%)\end{array}$ & \\
\hline
\end{tabular}

P-value >0.05 NS;

This table showed a statistically significant difference between general anesthesia and spinal anesthesia according to postoperative pain and needs of analgesia. (The time of postoperative needs of analgesia in pt. underwent LA under SA was delayed.

The evaluations of cosmetic effects were shown in each question was scored from 1 (dissatisfied) to 4 (satisfied) as showed in qestionnaires regarding cosmetic results. Outcomes regarding cosmetic effects showed that more patients of GSPLAP rated their scars well healed than did patients of CLAP. GSPLAP patients were more satisfied concerning the look of the scar than were patients in the CLAP Also GSPLAP patients were more likely to recommend the procedure to families and friend than were CLAP (Table 7)

Finally the degrees of patient's cosmetic satisfaction were:

- Excellent: in $28 \%(n=5)$ of the patients for CLAP and $89 \%(n=16)$ of the patients for GSPLAP.
- Very good: in $61 \%(n=11)$ of the patients for CLAP and $11 \%(n=2)$ of the patients for GSPLAP.

- Good: in $11 \%(n=2)$ of the patients for CLAP and $0 \%(\mathrm{n}=0)$ of the patients for GSPLA

Table 7: Comparison between group I: CLA and group II: Glove single port LA according to patient's satisfaction results

\begin{tabular}{|l|c|c|c|}
\hline $\begin{array}{c}\text { Patients } \\
\text { satisfaction } \\
\text { result }\end{array}$ & $\begin{array}{c}\text { CLAP } \\
(\mathbf{n}=18)\end{array}$ & $\begin{array}{c}\text { GSPLAP } \\
(\mathbf{n = 1 8})\end{array}$ & p-value \\
\cline { 1 - 3 } Excellent & $\mathbf{5}(28 \%)$ & $\mathbf{1 6}(89 \%)$ & \multirow{2}{*}{$0.001 * *$} \\
\hline Very Good & $\mathbf{1 1}(61 \%)$ & $\mathbf{2}(11 \%)$ & \\
\hline Good & $\mathbf{2}(11 \%)$ & $\mathbf{0}(0 \%)$ & \\
\hline
\end{tabular}

$\mathrm{P}$-value $<0.001 \mathrm{HS}$

\section{DISCUSSION}

Acute appendicitis (AA) is a common cause of acute abdominal pain with a life- time incidence between 7-9\%. Approximately $20-30 \%$ of children with acute abdominal pain referred to pediatric surgical services have AA. Another 50\% have benign, self-limiting, non- specific abdominal pain. The incidence of AA varies per age group ranging from one to six per 10,000 children annually under 4 years of age to 19 to 28 per 10,000 children under the age of 14 years ${ }^{[1,2]}$.

This study included 36 patients. The age ranged from 5 to 15 years and the mean age was (11.67) years in the CLA group and (12.06) years in the glove single port LA group. 20 patients were males and 16 patients were females.The laparoscopic approach should not result in a change of the indications for appendectomy. Any patient who, based on the overall assessment, requires and qualifies for a surgical exploration for suspected acute appendicitis is a likely candidate for the laparoscopic procedure. In addition, there are a number of patients in whom a diagnostic uncertainty persists despite multiple tests; in these patients, a diagnostic laparoscopy with a possible appendectomy may be indicated to clarify and treat the causative pathology ${ }^{[21]}$.A novel SILS technique modified by the introduction of a single port made with a surgical glove has been described more recently by several authors and some advantages are being advocated. It is noteworthy that the highpriced mono-port devices available on the market and the bent laparoscopic instruments carry an 
obvious increase in the overall costs for SILS procedures in comparison with the common multiport laparoscopy. Conversely, the use of a homemade surgical-glove port and standard straight laparoscopic instruments makes SGP-SILA as inexpensive, or even less expensive, than classic LA ${ }^{[22]}$.In our study, the mean operative time for CLAP was significantly lower than GSPLAP procedure. For CLAP it was 38.39 \pm 10.12 min (ranged from 26 to $75 \mathrm{~min}$ ) and it was $49.11 \pm 11.98 \mathrm{~min}$ (ranged from 38 to $86 \mathrm{~min}$ ) for GSPLAP. the operative time for the first 2 cases in Group II: Glove single port LA was more than 60 minutes because it took time by the operative team to get adapted to the new position of the instruments and difficulty in manipulating instruments which are so close to each other with limited triangulation and limited range of motion of the laparoscope and instruments but later on with performing more cases the time decreased to a range from 40 to 60 minutes. This is quite different to the previous studies that showed SILS group's operative time at about 5-10 minutes longer than CLA group's. However other study reported that the mean operative time for SILA was significantly lower than CLA procedure $(\mathrm{p}=0.049 ; 33 \pm 9$ min versus $41 \pm$ $12 \mathrm{~min})^{[23]}$.

In our study we used a 30-degree angle telescope for a better vision. Telescope is on the same axe with operative grasp. 30-degree angle telescope improves the triangulation for a better and safe procedure. Furthermore, a longer grasp size improves the feasibility of the procedure for better triangulation and no hands conflict between the two operative grasps and with the hand holding the camera.In our study, the intra operative monitoring of vital data regarding anesthesia: Including the mean blood pressure, pulse, and end tidal volume $\mathrm{Co} 2$ and $\mathrm{O} 2$ saturation \%. Showed no statistically significant difference between general and spinal anesthesia in each group (all are kept within normal ranges). The observation of the Post-operative pain and needs of analgesia regarding the surgical technique showed that laparoscopic procedures cause less post-operative pain than their conventional counterpart's. If we compare CLAP with GSPLAP, we observed that GSPLAP is less painful significantly than CLAP for the first postoperative hours $(\leq 3 \mathrm{hrs})$ as in GSPLAP there was no operative trocar only one incision throughout the umbilicus so, no abdominal wall trauma through parietal muscle was done and it probably reduced postoperative pain and improved recovery time after surgery.Under GA: the mean Time for first postoperative need of analgesia NSAID was $3.3 \pm 2.5$ (hrs) Ranged from 0.5 to $6 \mathrm{hrs}$. Under (SA) it was $6.54 \pm 2.54$ (hrs) Ranged from 4 to 12 (hrs) (The time of postoperative needs of analgesia in pt. underwent LA under SA is delayed. The injectable analgesic was usually required early in post-operative period after extubation when only GA was used. Spinal anesthesia (SA) has the advantage of providing analgesia and total muscle relaxation in a conscious and compliant patient and an uneventful postoperative recovery. At the same time, it also protects against the potential complications of General anesthesia (GA) ${ }^{[15]}$.

Hamad et al. reported that the benefit of prolonged analgesia after SA has also been noted. Intensity of pain was less in SA as compared to GA during early post-operative period until 6-h. There was no significant difference seen after this period ${ }^{[24]}$. Wound infection after laparoscopic appendectomy due to leakage of purulent exudates from appendix are common and can be avoided by placing the appendix in a sterile bag or into the trocar sleeve prior to removal from the abdomen. ${ }^{[25]}$ In our study the patients in CLAP suffered from some postoperative complications. There were two cases of umbilical cellulitis. Postoperative ileus occurred in 2 cases all patient complications resolved with symptomatic therapy. There was no postoperative intraabdominal abscess in either group, and there were no reoperations.In our study drain was inserted in 2 cases (due to blood accumulation after dissection of extensive adhesions) one drain in a case for CLAP and another in a case of GSPLAP but after conversion to multi-port LA). In our study early mobilization was advised and majority of the patients were usually discharged on the first post-operative day. Our patients were discharged from hospital after 24 up to 48 hours. The mean postoperative hospital stay was $337 \pm 9.90$ hours for CLAP and $29 \pm 8.46$ hours for GSPLAP. Teoh $\boldsymbol{e t} \boldsymbol{a l}$. reported in their study that they could not find any statistically [26]. Significant differences in admission days between the two groups were detected. Taking into consideration the fact that three surgical instruments need to be inserted through a single incision at the same time in the case of SILS, a larger incision in the navel, than in the CLA 
technique, is required. Hence, more intense pain or surgical wound infection is anticipated in the SILS technique based on such a theoretical basis ${ }^{[27]}$. Outcomes regarding cosmetic effects showed that more patients of GSPLAP rated their scars well healed than did patients of CLAP. GSPLAP patients were more satisfied concerning the look of the scar than were patients in the CLAP. Also, GSPLAP patients were more likely to recommend the procedure to families and friend than were group I: CLA. This result showed that there was a certain advantage of performing the single port surgery compared to the standard procedure. Although one study reported that the cosmetic outcomes have not been reported to be significantly different between single-incision and 3-port laparoscopy and rather a perceived better perception of cosmesis by the patient or an advertised improvement of cosmesis has been reported ${ }^{[27]}$.

\section{CONCLUSION}

The glove single-port laparoscopic appendectomy it is a novel SILS technique modified by the introduction of a single port made with a surgical glove. The biggest advantage of our homemade glove port and our procedure is that it is extremely cheaper than the other commercial devices. Using a combination of $0.5 \%$ hyperbaric bupivacaine and a fentanyl provided effective anesthesia for laparoscopic appendectomy it offers better pain management for the patients, earlier recovery and less operating room costs.

\section{RECOMMENDATION}

We recommend an increasing use of the glove single-port laparoscopic appendectomy as it became rapid and safe also increasing use spinal anesthesia for laparoscopic appendectomy especially in patients with risks for general anesthesia.

\section{REFERENCES}

1. Buicko L J, Parreco J, Abel Net al. (2017): Pediatric laparoscopic appendectomy, risk factors, and costs associated with nationwide readmissions. J. Surg. Res. ,215:245-249.

2. Yamanaka S, Skarsgard ED and Goldman RD (2018): conservative therapy for appendicitis in children . Can. Fam. Physician, 64(8): 574-576.
3. Semm K (1983): Endoscopic appendectomy. Endoscopy, 15:59-64.

4. Sweeney KJ and Keane FB (2003): Moving from open to laparoscopic appendectomy. BJS., 20:257 -258.

5. Konstadoulakis $\mathbf{M}$, Gomatos $\mathbf{P}$, Antonakis $\mathbf{T}$ et al. (2006): Two-trocar laparoscopicassisted appendectomy versus conventional laparoscopic appendectomy in patients with acute appendicitis. Journal of Lap Endosc and Advanced Surgical Techniques, 16(1):27-32

6. Horvath $P$, Lange $J$, Bachmann $R$ et al. (2017): Comparison of clinical outcome of laparoscopic versus open appendectomy for complicated appendicitis, Surg. Endosc., 31(1):199-205.

7. Abe T, Nagaie T and Miyazaki M (2013): Risk factors of converting to laparotomy in laparoscopic appendectomy for acute appendicitis. Clin. Exp. Gastroenterol.,6:109-114.

8. Maitra K.T, Ekramullah M, Mondol K et al. (2017): Post-surgical outcomes of laparoscopic appendectomy. IMC. J. Med. Sci., 11(1): 15-18.

9. Kim H J, Kim Y, Park K et al. (2015): Single-incision laparoscopic appendectomy versus conventional laparoscopic appendectomy. Ann. Surg., 262: $1054-1058$.

10. Aly E, Black H, Haroon $R$ et al. (2016): Single incision laparoscopic appendicectomy versus conventional three-port laparoscopic appendicectomy: A systematic review and meta-analysis. Int. J. Surg.,35:120-128.

11. Pelosi MA and Pelosi MA (1992). Laparoscopic appendectomy using a single umbilical puncture (minilaparoscopy). J. Reprod. Med., 37:588-594.

12. Binenbaum SJ, Teixeira JA, Forrester G J et al. (2009): Single-incision laparoscopic cholecystectomy using a flexible endoscope. Arch Surg., 144(8):734-738.

13. Dutta $S$ (2009): Pediatric general surgery. In: Anesthesiologists Manual of Surgical Procedure. $4^{\text {th }}$ Edition. New York: Lippincott Williams \& Wilkins,pp.1301-1311.

14. Gurudatta KN and Arif M (2014): A cclinical study of comparison between general anesthesia and spinal anesthesia for lower abdominal laparoscopic surgeries. Sch. J. App. Med. Sci., 2(3): 1127-1133. 
15. Sinha R, Gurwara AK and Gupta SC (2009): Laparoscopic cholecystectomy under spinal anesthesia. J. Laparoendosc. Adv. Surg. Tech., 19: 323- 327.

16. Bessa SS, El-Sayes IA and Abdel-Baki NA et al. (2010): Laparoscopic Cholecystectomy Under Spinal Versus General Anesthesia: A Prospective, Randomized Study. J Laparoendosc Adv Surg Tech A., 20: 515-520.

17. Khan MN, Fayyad T and Cecil TD et al. (2007): Laparoscopic versus open appendectomy: the risk of postoperative infectious complications. JSLS. , 11: 363-367.

18. Gagner $M$ and Garcia-Ruiz A (1998): Technical aspects of minimally invasive abdominal surgery performed with needlescopic instruments. Surg. Laparosc. Endosc., 8:171- 179.

19. Valioulis I, Hameury F and Dahmani L et al. (2001); Laparoscope assisted appendectomy in children: The two-trocar technique. Eur. J. Pediatr. Surg., 11:391-394.

20. Aurelian Binet, Karim Braïk and Francois Lengelle et al. (2018): Laparoscopic one port appendectomy. Journal of Pediatric Surgery, 53( 11): 2322-2325.

21. Katkhouda N (2009): Laparoscopic surgery of the appendix. In: Mastery of Endoscopic and Laparoscopic Surgery. Indications and Techniques. $3^{\text {rd }}$ Edition. Lippincott Williams and Wilkins. Chapter 46. USA. pp: 462-467.

22. Di Saverio S (2014): Emergency laparoscopy: a new emerging discipline for treating abdominal emergencies attempting tominimize costs and invasiveness and maximize outcomes and patients' comfort. J. Trauma Acute Care Surg., 77:338-350.
23. Aurelian Binet, Karim Braïk and Francois Lengelle et al. (2018): Laparoscopic one port appendectomy: Evaluation in pediatric surgery Journal of Pediatric Surgery, 53 (11): 23222325.

24. Van der Voort M, Heijnsdijk EA and Gouma DJ(2004): Bowel injury as acomplication of laparoscopy. $\mathrm{Br} \quad \mathrm{J}$ Surg.,91:1253-1258.

25. Salö1 M, Emil Järbur $E$ and Hambraeus $M$ et al. (2016): two-trocar appendectomy in children-description of technique and comparison with conventional laparoscopic appendectomy. BMC Surgery, 16:52.

26. Mishra RK, Hanna GB and Cuschieri A (2011): Laparoscopic versus open appendicectomy for the treatment acute appendicitis . World Laparascopy Hospital Journal, 7: 1-16.

27. Esposito C, Escolino M, Till H et al. (2016): One-trocar versus multiport hybrid laparoscopic appendectomy: What's the best option for children with acute appendicitis? Results of an international multi centric study. Surg Endosc., 30: 4917-4923.

28. Teoh AY, Chiu PW and Wong TC et al. (2011): A case-controlled comparison of single-site access versus conventional three port laparoscopic appendectomy. Surg Endosc., 25: $1415-9$. 